\title{
The Functional Characteristics of Schwann Cells Cultured from Human Peripheral Nerve after Transplantation into a Gap within the Rat Sciatic Nerve
}

\author{
A. D. O. Levi, ${ }^{1}$ V. Guénard, ${ }^{1}$ P. Aebischer, ${ }^{2}$ and R. P. Bunge ${ }^{1}$ \\ ${ }^{1}$ The Miami Project to Cure Paralysis, and the Department of Neurological Surgery, University of Miami School of \\ Medicine, Miami, Florida 33136 and ${ }^{2}$ Division de Recherche Medicale, Centre Hospitalier Vaudois, 1011 Lausanne, \\ Switzerland
}

The use of human Schwann cells (SCs) in transplantation to promote regeneration in central and peripheral neural tissues must be preceded by efforts to define the factors that regulate their functional expression. Adult-derived human SCs can be isolated and purified in culture, but the culture conditions that allow their full differentiation have not yet been defined. We tested the functional capacity of these cells to enhance axonal regeneration and myelinate regenerating axons in vivo by transplanting them into the damaged PNS of an immune-deficient rat. SCs were purified from human peripheral nerve obtained from organ donors. Semipermeable guidance channels were filled with a $30 \% \mathrm{Ma}$ trigel containing solution with or without human SCs suspended at a density of $80 \times 10^{6} \mathrm{cells} / \mathrm{ml}$. Channels were implanted within an $8 \mathrm{~mm}$ gap of the transected sciatic nerve of nude female rats for a period of 4 weeks. Survival of the transplanted human SCs was established by dissociating nerve explants taken from the regenerated cable (after first placing them in culture for $5 \mathrm{~d}$ ) and staining individual cells for a primate-specific NGF receptor (PNGFr) and S100. Only one-half of the S100-positive cells stained for the PNGFr, which indicated that the regenerated cable contained an approximately equal number of human and rat (host) SCs. The presence of some human myelin segments was confirmed by immune staining with an HNK-1 antibody that specifically labels human but not rat myelin. The majority of the myelin segments in the regenerated cable, however, were produced by the rat SCs. The number of myelinated axons and the cross-sectional area of the cable were significantly greater in channels seeded with human SCs when compared to channels containing the diluted Matrigel solution alone. We conclude that purified cultured human SCs can survive and substantially enhance axonal regeneration when trans-

\footnotetext{
Received Nov. 20, 1992; revised Aug. 9, 1993; accepted Aug. 19, 1993.

Ihis work was supported by NS09923 (NIH/NINDS), Gliatech Inc., and The Miami Project to Cure Paralysis. A.D.O.L. is a fellow of the Medical Research Council of Canada. We are grateful to Drs. N. Latov and J. Roder for their helpful comments. We thank Leeanne Lipson and Margaret Bates for their excellent technical assistance. We also thank Dr. J. Klose for assisting with the statistical analysis, and Les Olson, J. D. Waters, and the University of Miami transplant tcam for supplying human tissue. The $217 \mathrm{c}$ antibody was a generous gift from Dr. J. de Vellis and the Po antibody from Dr. D. Colman.

Correspondence should be addressed to Dr. A. Levi, The Miami Project, University of Miami School of Medicine, 1600 NW 10th Avenue, R-48, Miami, FL 33136 .

Copyright $@ 1994$ Society for Neuroscience $0270-6474 / 94 / 141309-11 \$ 05.00 / 0$
}

planted into the injured PNS of an immune-deficient rat. Some of the transplanted human SCs are capable of myelinating regenerating rat axons but are less successful than the host SCs.

[Key words: human Schwann cells, NGF receptor, myelinated axons, HNK-1, nerve regeneration, polymeric tube]

For almost a century, it has been known that the peripheral nerve microenvironment promotes nerve fiber regeneration (for revicw, sce Ramon y Cajal, 1928). More recently, modern neuroanatomical methods have allowed a clear demonstration that this microenvironment is also conducive to CNS axonal regeneration (David and Aguayo, 1981). Viable Schwann cells (SCs) appear to be a prerequisite for successful regeneration to occur in the CNS (Kromer and Cornbrooks, 1987), as freeze-dried grafts devoid of SCs do not engender axon growth (Smith and Stevenson, 1986; Berry et al., 1988). Similarly, when SCs are not permitted to comigrate with regenerating peripheral nerve axons into an acellular peripheral nerve graft (Hall, 1986b), axonal elongation is significantly impeded. SCs have been shown to have a number of roles in promoting axonal regeneration. These include the synthesis of at least three neurotrophic factors: NGF (Heumann et al., 1987), brain-derived neurotrophic factor (Acheson et al., 1991), and ciliary neurotrophic factor (Friedman et al., 1992); the reexpression of receptors for certain neurotrophins (Taniuchi et al., 1986); the claboration of ccll adhcsion molecules (Daniloff et al., 1986; Martini and Schachner, 1986); and the synthesis of basement membrane components (Bunge and Bunge, 1983).

Considering the importance of the cellular component of the peripheral nerve microenvironment, the construction of a cellular prosthesis consisting of human SCs could conceivably have several therapeutic applications. These would include transplantation of such a prosthesis into areas of damaged spinal cord (Paino and Bunge, 1991; Xu et al., 1992) in an effort to influence regeneration of interrupted central axons. In addition, the repair of complex peripheral nerve injuries could be simplified. In those cases in which the gap length that needs to be bridged is long or the geometry of the proximal or distal stumps complex, a cellular prosthesis could be used as an alternative to multiple autografts (Millesi, 1990).

Certain of the techniques required to prepare an autologous cellular prosthesis from human peripheral nerve have recently been described. Morrissey et al. (1991a) have reported a novel method of isolating and purifying SCs from adult peripheral nerve. As large numbers of the patient's own cells would be 
required to create such a prosthesis, an autotransplantation paradigm is dependent upon being able to expand these cells in culture with mitogens without transformation and have them retain their functional (i.e., myelination) capabilities. Rutkowski et al. (1992) have recently described tissue culture studies on human SCs that identifies a combination of mitogens that increases DNA synthesis in these cells.

The ability of adult derived rat SCs to myelinate dorsal root ganglion (DRG) axons in culture has been well described (Morrissey et al., 1991a). However, adult-derived human SCs will associate but fail to myelinate either rat- or human-derived DRG axons (Morrissey et al., 1991b) using similar defined culture conditions. The human SC's' inability to function under these conditions may be due to an intrinsic defect of human SCs that have been isolated in this manner or may be due to the restrictions of the imposed culture conditions. These culture conditions are sufficient to support full function of rat but not the human SCs.

This inability to obtain full human SC function in culture is in contrast to observations made on the transplantation of human peripheral nerves into rodent hosts. Aguayo et al. (1977, 1978, 1979) have presented evidence that SCs from human xenografts are capable of myelinating regenerating peripheral axons from mice that have been immunosuppressed by injections of antilymphocytic serum. Since it has been suggested that human SCs introduced as xenografts are capable of myelinating rodent axons, we devised an in vivo study to determine if this functional capacity is retained after purifying and culturing SCs from adult human peripheral nerve.

Some of our observations have been published in abstract form (Levi et al., 1992).

\section{Materials and Methods}

Preparation of purified human SC cultures. Human peripheral nerves were obtained from organ donors by the transplant procurement team of the University of Miami School of Medicine. The nerves were used for subsequent study if the donors had a negative serology for infectious agents and if their past medical history was negative for any diseases predisposing to a peripheral neuropathy. The nerves (phrenic, intercostal, or lumbosacral plexus) were harvested within $30 \mathrm{~min}$ of aortic clamping and stored in RPMI (GIBCO Laboratories, Grand Island, NY) at $4^{\circ} \mathrm{C}$ for no more than $24 \mathrm{hr}$. Each peripheral nerve was prepared for culture according to the protocol of Morrissey et al. (1991a). This includes washing the nerve three times in Liebovitz's L1 5 (GIBCO), stripping the epineurium of the nerve, and removing individual fascicles from the remaining perineurium. The individual fascicles were then cut into 1 -mm-long explants and $12-15$ explants were then placed in 35 $\mathrm{mm}$ culture dishes. The prepared nerves were kept in a humidified atmosphere with $5 \% \mathrm{CO}_{2}$ and the medium was replaced two times per week with Dulbecco's Modified Eagle's Medium (DMEM; GIBCO) with $10 \%$ fetal calf serum (FCS; Hyclone Laboratories, Logan, UT). The individual explants were transplanted to new dishes after a confluent monolayer of predominantly fibroblasts had been generated as an outgrowth. This occurred in approximately 7-14 d. After three to five transplantations, the nerve explants were largely dcplctcd of fibroblasts and they were then dissociated according to the protocol of Pleasure et al. (1986).

Multiple explants (45-60) were pooled and placed in 1-2 $\mathrm{ml}$ of an enzyme cocktail consisting of $1.25 \mathrm{U} / \mathrm{ml}$ dispase (Boehringer Mannheim Biochemicals Germany), 0.05\% collagenase (Worthington Biochemicals Corp., Freehold, NJ), and 15\% FCS in DMEM. The explants were left in enzyme overnight and gently triturated the following morning with a straight glass borosilicate pipette until individual explants could no longer be recognized. The cells were then washed in $\mathrm{L} 15$ and $10 \%$ FCS and plated on $100 \mathrm{~mm}$ culture dishes coated with $200 \mu \mathrm{g} / \mathrm{ml}$ polyL-lysine (PLL; Sigma, St. Louis, MO).

Characterization of dissociated SCs in culture. On the day the semipermeable guidance channels were filled with the purified human SCs, a small fraction of the dissociated cells were seeded on Aclar (Allied Signal, Pottsville, PA) minidishes coated with ammoniated collagen (Kleitman et al., 1991). The next day the cells were immunostained in the living state with a monoclonal antibody to a primate-specific NGF receptor (PNGFr; American Type Culture Collection, Rockville, MD; HB 8737) to assess Schwann cell purity. After blocking with $10 \%$ norma goat serum (NGS), the PNGFr antibody (tissue culture supernatint) was applied for $45 \mathrm{~min}$. Cells were then incubated with a fluorescein goat anti-mouse secondary antibody (1:100; Cappel Organon, Teknika Corp. West Chester, PA) for $45 \mathrm{~min}$. The culture was fixed with a $4 \%$ paraformaldehyde in $0.1 \mathrm{M} \mathrm{PO}_{4}$ buffer for $10 \mathrm{~min}$ and then mounted on glass slides using a glycerol/phosphate-buffered saline solution (Citifluor Ltd., London) containing $5 \mu \mathrm{M}$ Hoechst dye (Hoechst 33342, Sigma). The Hoechst dye binds DNA and was used to image all the nuclei within the culture under the fluorescence microscope. Human Schwann cells were identified as they were PNGFr positive and Hoechst positive; fibroblasts appeared as polymorphic flat cells that were Hoechst positive but PNGFr negative.

The immunoreactivity of the dissociated cultured human SC preparation to the mouse monoclonal antibody HNK-1 (anti-Leu 7; Becton Dickinson Inc., San Jose, CA) was tested both in the live and permeabilized, fixed state. Live cultures were first blocked with $10 \%$ NGS, and then incubated with HNK-1 (undiluted) for $45 \mathrm{~min}$. The fluorescein goat anti-mouse secondary (1:100) was also applied for $45 \mathrm{~min}$, and then the cells were fixed with $4 \%$ paraformaldehyde in phosphate buffer. To assess the immunoreactivity in the fixed permeabilized state, the cells were first exposed to $4 \%$ paraformaldehyde for $10 \mathrm{~min}$ followed by $0.03 \%$ Triton X-100 in $4 \%$ paraformaldehyde for $10 \mathrm{~min}$. The blocking solution, the HNK-1 antibody, and fluorescein goat anti-mouse were then applied as described above.

Filling, implantation, and retrieval of the guidance channels. PAN/ PVC (60:40 polyacrylonitrile/vinylchloride) tubes were manufactured according to the technique of Cabasso (1980) and Aebischer et al. (1991). The semipermeable tubes had an internal diameter of $1.12 \mathrm{~mm}$ and a wall thickness of $0.126 \mathrm{~mm}$, and contained pores within the walls that provided a barrier to molecules greater than 50,000 Da molecular weight. The channels were cleaned prior to filling according to the protocol of Aebischer et al. (1988).

The dissociated cells were lifted off the PLL-coated culture plates after rinsing twice with $\mathrm{Ca}^{2+} / \mathrm{Mg}^{2+}$-free Hanks' Balanced Salt Solution (HBSS; GIBCO) and exposing them to trypsin $(0.05 \%)$ and EDTA $(0.02 \%)$ (Sigma) in HBSS for $5-10$ min at $37^{\circ} \mathrm{C}$. The cells were collected and rinsed twice in L15 and 10\% FCS. Cells were counted on a hemocytometer, and then diluted into a calculated volume of Matrigel (Collaborative Research Inc., Bedford, MA) : DMEM (M/D), in a ratio of $30: 70(\mathrm{v} / \mathrm{v})$, so that the final cellular concentration would equal $80 \times$ $10^{6}$ cells/ml [M/D + HSC (human SCs)]. Control channels contained only $M / D$ in a similar volumetric ratio of $30: 70$. The $M / D$ matrix, with or without cells, was kept at $4^{\circ} \mathrm{C}$ to facilitate gentle aspiration of the preparation into tubing that had been ligated to a blunted \#21 needle attached to a $5 \mathrm{cc}$ syringe. One-centimeter segments of the filled tube were cut and then capped with PAN/PVC copolymer glue. The filled channels were kept in DMEM containing penicillin/streptomycin $(50$ $\mathrm{U} / \mathrm{ml}$ and $50 \mu \mathrm{g} / \mathrm{ml}$, respectively) overnight at $37^{\circ} \mathrm{C}$.

To characterize the arrangement of the Schwann cells within the filled channels, some cell filled tubes were kept in culture for $24 \mathrm{hr}$ at $37^{\circ} \mathrm{C}$ in DMEM containing penicillin/streptomycin. The tubes were then fixed in $3 \%$ paraformaldehyde and $2.5 \%$ glutaraldehyde, osmicated in $2 \%$ $\mathrm{OsO}_{4}$, dehydrated in graded ethanols, critical point dried, and then sprayed with gold. The preparation was then viewed with a JEOL 35 scanning electron microscope.

Athymic female nude rats (Taconic, Germantown, NY) weighing 135$210 \mathrm{gm}$ were handled and maintained according to NIII guidelines for the care and use of laboratory animals. They were anesthetized with pentobarbital (Nembutal) at a dosage of $27.1 \mathrm{mg} / \mathrm{kg}$. Their sciatic nerve was exposed using a muscle-splitting incision of the posterolateral thigh musculature. A 5-6 $\mathrm{mm}$ segment of the sciatic nerve was removed at midthigh, resulting in an $8 \mathrm{~mm}$ gap. This was repaired by introducing the proximal and distal stumps of the transected sciatic nerve $1 \mathrm{~mm}$ within the openings (after removing the caps) of either end of the matrix filled channel and anchoring them to the tube with a single 10-0 nylon ( $\mathrm{S} \& \mathrm{~T}$ ) suture. The wound was then closed in layers. The rats were quarantined in rooms containing HEPA filters and fed autoclaved food and water ad libitum. All animals were maintained for 4 weeks. Rats whose grafts were analyzed for cellular content using cell culture techniques or grafts analyzed by immunostaining frozen sections were killed 


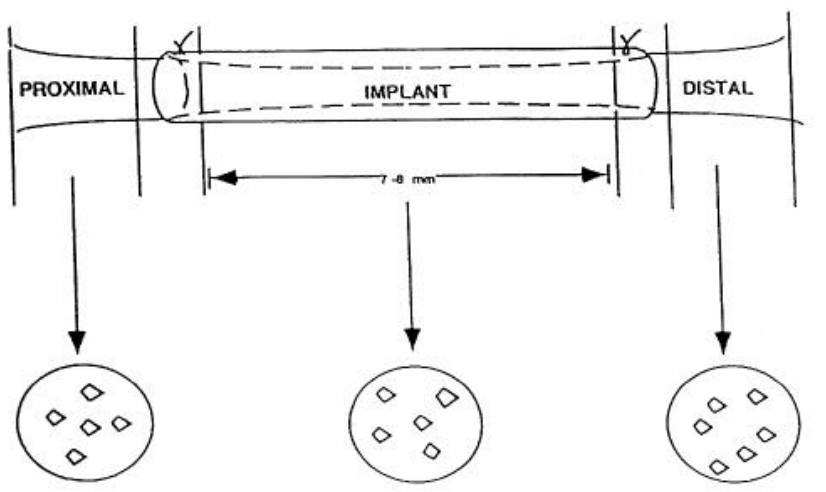

EACH SEGMENT ISOLATED, CUT INTO $1 \times 1 \mathrm{~mm}$ EXPLANTS, AND PLACED INTO CULTURE FOR 5 DAYS TO ALLOW FOR WALLERIAN DEGENERATION

Figure 1. Schematic diagram demonstrating the technique of isolating and culturing SCs from the regenerated cable and the proximal/distal stumps 4 weeks postimplantation (see Materials and Methods).

by administering a deep anesthetic of pentobarbital and removing the grafts, including the proximal and distal stumps, without perfusing the animals. Rats whose grafts were analyzed morphometrically were also deeply anesthetized and then perfused transcardially at a pressure of $120-140 \mathrm{~mm} \mathrm{Hg}$, with normal saline followed by a solution containing $4 \%$ paraformaldehyde and $1.0 \%$ glutaraldehyde in $0.1 \mathrm{~m}$ phosphate buffer.

Evaluation of the cellular content of regenerated cables from channels implanted with human SCs, and the proximal and distal stumps of the repaired sciatic nerve. The implants $(\mathrm{M} / \mathrm{D}+\mathrm{HSC} ; n=8)$ including approximately $5 \mathrm{~mm}$ of the proximal and distal stumps (Fig. 1) were retrieved under sterile conditions from the operated animals after 4 weeks and rinsed three times in L15. The guidance channel was removed, exposing the regenerated cable within. The middle 7-8 $\mathrm{mm}$ of the cable was sharply transected and the epineurium-like sheath was removed. The regenerated cable was then cut into $1 \mathrm{~mm}^{2}$ explants and placed on collagen-coated Aclar mini dishes. Similarly, $5 \mathrm{~mm}$ segments of the proximal and distal stumps were taken at least $1 \mathrm{~mm}$ away from the entry of these segments into the guidance channel. Their epineurium was also removed, and the explants were placed in culture for $5 \mathrm{~d}$ to allow for upregulation of the SC nerve growth factor receptor (Taniuchi et al., 1988). Cultures were fed DMEM containing $10 \%$ FCS every $2 \mathrm{~d}$. After $5 \mathrm{~d}$, individual culture groups were then placed in the enzyme cocktail overnight and dissociated (see above) the following day using a flame-narrowed borosilicate pipette $(0.5 \mathrm{~mm})$. The cells were then washed twice in L15 containing 10\% FCS and replated on collagencoated Aclar minidishes.

The next day, double immunostaining was done on both nondissociated explants and cells from the dissociated explants. Initially the cultures were stained in the living state for the PNGFr for $45 \mathrm{~min}$. In certain cases, an antibody recognizing the rat NGFr-217c (undiluted tissue culture supernatant) - but not the human NGFr was utilized. This was followed by a fluorescein-conjugated goat anti-mouse antibody. The cells were then fixed in $4 \%$ paraformaldehyde and then permeabilized in $4 \%$ paraformaldehyde containing $0.03 \%$ Triton-X 100 . After reblocking the preparation with the $10 \%$ NGS in $0.1 \mathrm{~m}$ phosphate buffer, the cultures were incubated with anti-S100 antibody (1:100; Dakopatts, Glostrup, Denmark) for $45 \mathrm{~min}$, washed with L15, and then incubated with a rhodamine-conjugated goat anti-rabbit secondary antibody (1: 50; Cappel/Organon) for $35 \mathrm{~min}$. The cultures were then mounted on slides with a drop of Citifluor containing Hoechst dye. In each dissociated cell group, 20 random fields that contained cells were counted for human SCs $\left(\mathrm{S}_{100}{ }^{+}, \mathrm{PNGFr}^{+}\right)$, rat SCs $\left(\mathrm{S}_{100}{ }^{+}, \mathrm{PNGFr}^{-}\right)$, and fibroblasts and other cells ( $\left.\mathrm{S} 100^{-}, \mathrm{PNGFr}^{-}\right)$.

Immunostaining of frozen sections of control nerves and regenerated cables. Implanted channels (M/D, $n=7 ; \mathrm{M} / \mathrm{D}+\mathrm{HSC}, n=7)$ were retrieved from the operated animals and placed immediately in Lipshaw embedding medium and frozen to $-80^{\circ} \mathrm{C}$. Cross- and longitudinal sections (7-12 $\mu \mathrm{m}$ thick) of the implant were cut using a cryostat and mounted on PLL-coated glass slides. To immunostain, sections were warmed briefly to room temperature and then exposed to $100 \%$ alcohol for $1 \mathrm{~min}$. The sections were then blocked with a solution containing
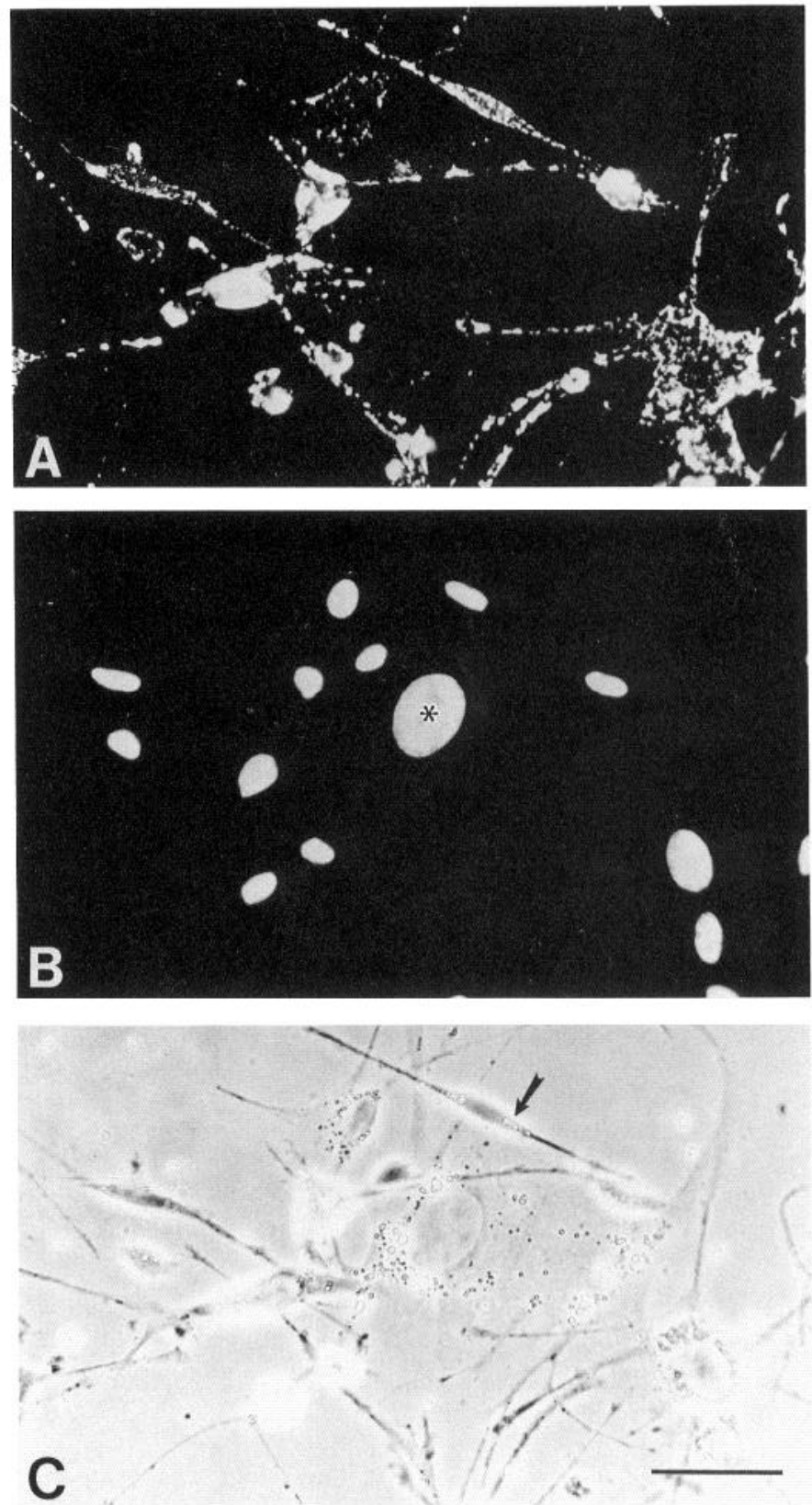

Figure 2. Characterization of a preparation of dissociated human SCs. $A$, Cells dissociated from human peripheral nerve explants prior to implantation immunostained with PNGFr. $B$, The same field viewed with a Hoechst filter demonstrates that most cells are PNGFr positive, indicating a high SC purity. Fibroblasts $\left({ }^{*}\right)$ have a large, rounded nucleus, but do not stain with PNGFr. $C$, Same field viewed in phase shows that a large proportion of the human SCs contain phase refractile intracellular inclusions (arrow). Scale bar, $50 \mu \mathrm{m}$.

$10 \%$ NGS for $20 \mathrm{~min}$. The HNK-1 antibody (undiluted, tissue reagent) was then applied for $16 \mathrm{hr}$ at $4^{\circ} \mathrm{C}$. The secondary antibody (fluoresceinconjugated goat anti-mouse) was applied for $45 \mathrm{~min}$ at $37^{\circ} \mathrm{C}$. Sections were then mounted with Citifluor containing Hoechst dye. The Po antibody $(1: 300)$ when used as the primary antibody was similarly applied, but a rhodamine-conjugated goat anti-rabbit $(1: 50)$ would then be used as a secondary antibody. Adult human peripheral nerve and nude rat sciatic nerves that served as controls were prepared in an identical manner.

Morphometric analysis of the regenerated cable. Implants $(n=14)$ retrieved from animals to be analyzed morphometrically were transected at their midpoint and then postfixed overnight at $4^{\circ} \mathrm{C}$ in $4 \%$ 

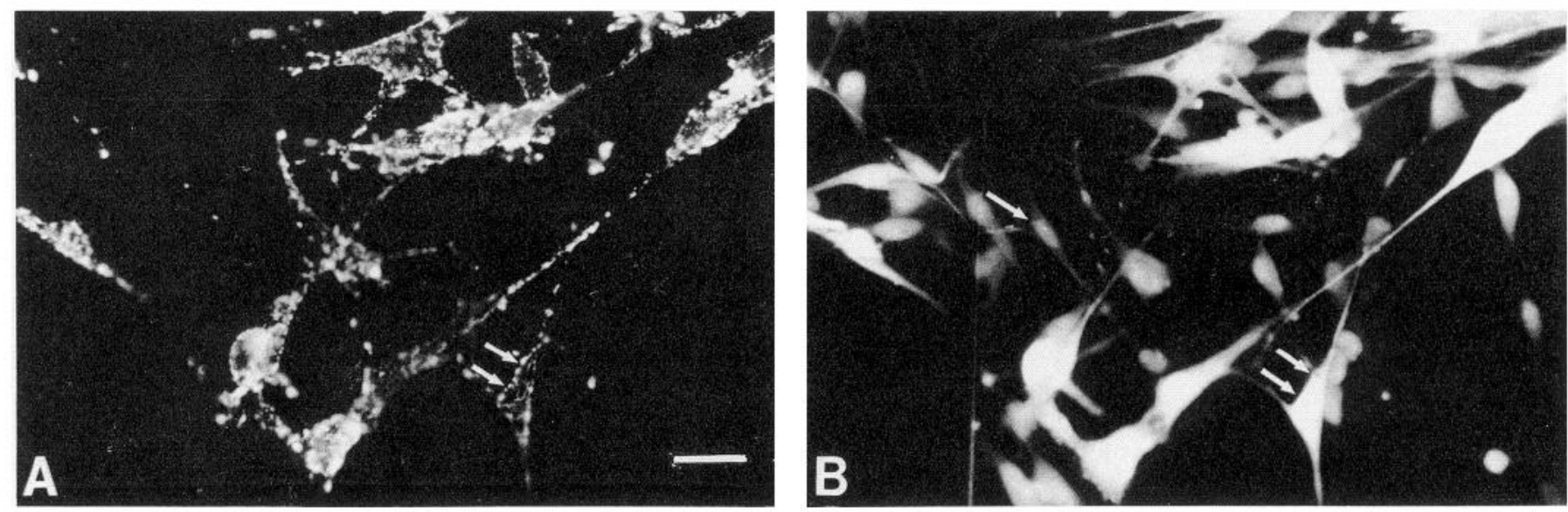

Figure 3. Characterization of cells taken from the regenerated cables. $A$, Five-day-old explants from the regenerated cable dissociated, immunostained with PNGFr, and viewed with a fluorescein filter. $B$. The same field viewed with a rhodamine filter identifies S100-positive cells, some of which colocalize with PNGFr immunostaining (double arrows) and indicate human-derived SCs. The smaller bipolar cells (single arrow) that stain only with S100 represent rat SCs. Scale bar, $50 \mu \mathrm{m}$.

paraformaldehyde and $0.5 \%$ glutaraldehyde in $0.1 \mathrm{M}$ phosphate buffer. The nerves were then washed three times in $0.15 \mathrm{~m}$ phosphate buffer, osmicated for $1 \mathrm{hr}$ in $1 \%$ osmium tetroxide in $0.1 \mathrm{M}$ phosphate buffer, dehydrated in graded ethanols, exposed to propylene oxide twice for 1 $\mathrm{hr}$ each, and then embedded in an Epon resin (Electron Microscopy Sciences, Fort Washington, PA). The resulting blocks were cut using a microtome so that semithin sections were obtained from points of the regenerated cable $2,4,6$, and $8 \mathrm{~mm}$ distal to the proximal suture. The sections were stained with toluidine blue and the number of myelinated axons and cable surface area were calculated with the aid of a grid at $630 \times$ magnification.

In several cases ultrathin sections were taken from cable midpoints, counterstained with lead citrate and uranyl acetate and viewed on a Philips Electronic Instruments, Inc. (Mahwah, NJ), model 300 transmission electron microscope (TEM). The number of unmyelinated axons within the regenerated cables from both groups was estimated in the following manner. Cables to be analyzed from each group [M/D $(n$ $=3) \mathrm{vs} \mathrm{M} / \mathrm{D}+\mathrm{HSC}(n=3)]$ were selected on the basis that they represented those being closest to the group mean of myelinated axons counted by light microscopy. A ratio of unmyelinated axons to myelinated axons (Jenq and Coggeshall, 1986b) was calculated by counting

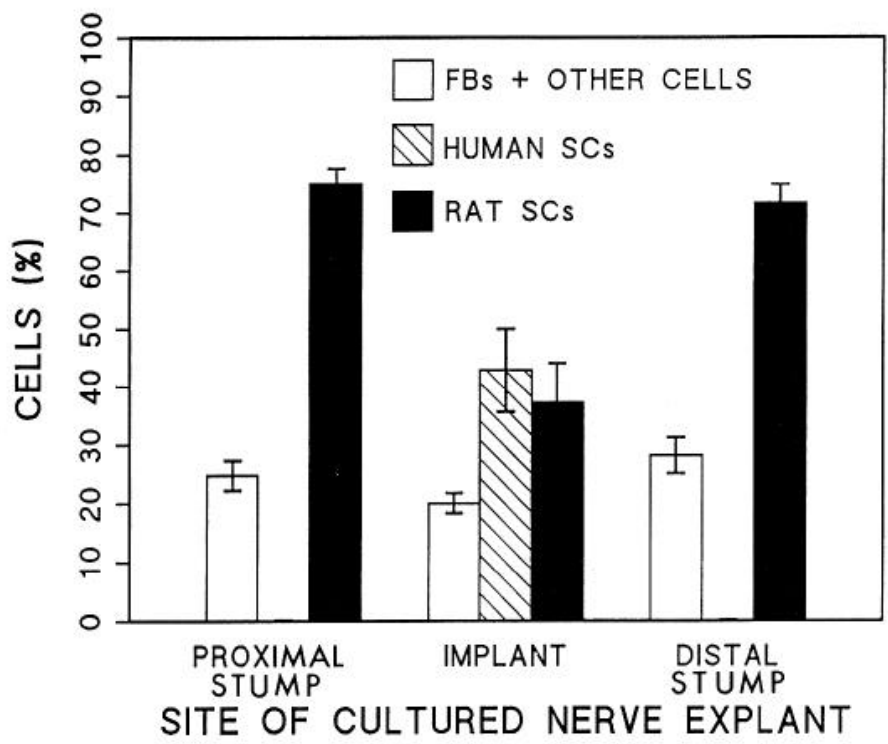

Figure 4. Distribution of human SCs, rat SCs, fibroblasts, and other cells in dissociated 5-d-old explants of cultures from the regenerated cable, and the proximal and distal stumps of the repaired nude rat sciatic nerve $(n=8)$. Data represent means \pm SEM. axons from photographs of 10 random areas of the cable midpoints at a magnification of $5800 \times$ using the TEM. The average number of unmyelinated axons at the cable midpoint in both groups was then approximated by multiplying this ratio by the known number of myelinated axons previously counted on toluidine blue-stained sections at the same level.

Statistical analysis. All data are presented as the means \pm SEM. The data were subjected to a mixed-design analysis of variance (ANOVA) using a one between [M/D alone vs M/D + HSC $\left(80 \times 10^{6}\right.$ cells $\left.\left./ \mathrm{ml}\right)\right]$ and one repeated measure [i.e., distances $(2,4,6,8 \mathrm{~mm})]$. A commercially available software program, STATISTICA (StatSoft Inc., Tulsa, OK), was used for all statistical analysis.

\section{Results}

\section{Human SC cultures}

The age of human donors ranged from 3 to 63 years $(n=9)$, with a mean age of 26.7. The purity of human SCs obtained from each donor, as determined by the proportion of cells that stained positively for PNGFr, ranged from 88 to $96 \%$, with a mean of $91.8 \%$ (Fig. $2 A, B$ ). When on a collagen-coated substratum, most of the human SCs cells had a spindle-shaped appearance but some displayed multiple processes. They tended to be larger than similarly prepared SCs obtained from rat peripheral nerve. Another striking difference between the rat and human SCs in culture was the presence within a large proportion of the human SCs of many phase refractile intracellular inclusions (Fig. 2C). These inclusions were rounded and tended to be located in the perinuclear region of the human SCs.

Longitudinally arranged cables of cells were seen in scanning electron micrographs of channels seeded with human SCs observed after $24 \mathrm{hr}$ in culture (data not shown). This phenomenon of syneresis leading to formation of a central cable of aligned SCs was very similar to the rat SC cables illustrated by Guénard et al. (1992).

\section{Evaluation of the cellular content of regenerated cables from channels implanted with human SCs, and the proximal and distal stumps of the repaired sciatic nerve}

Human SCs could be readily identified from explants of the regenerated cable as they stained for both PNGFr and S100 (Fig. $3 A, B$ ). The rat SCs also stained for $\mathrm{S} 100$, but not PNGFr. The intensity of $\mathrm{S} 100$ staining in the rat SCs was relatively less than that in human SCs. The rat SCs also tended to be smaller and more rounded than the human SCs. Some cells from the 

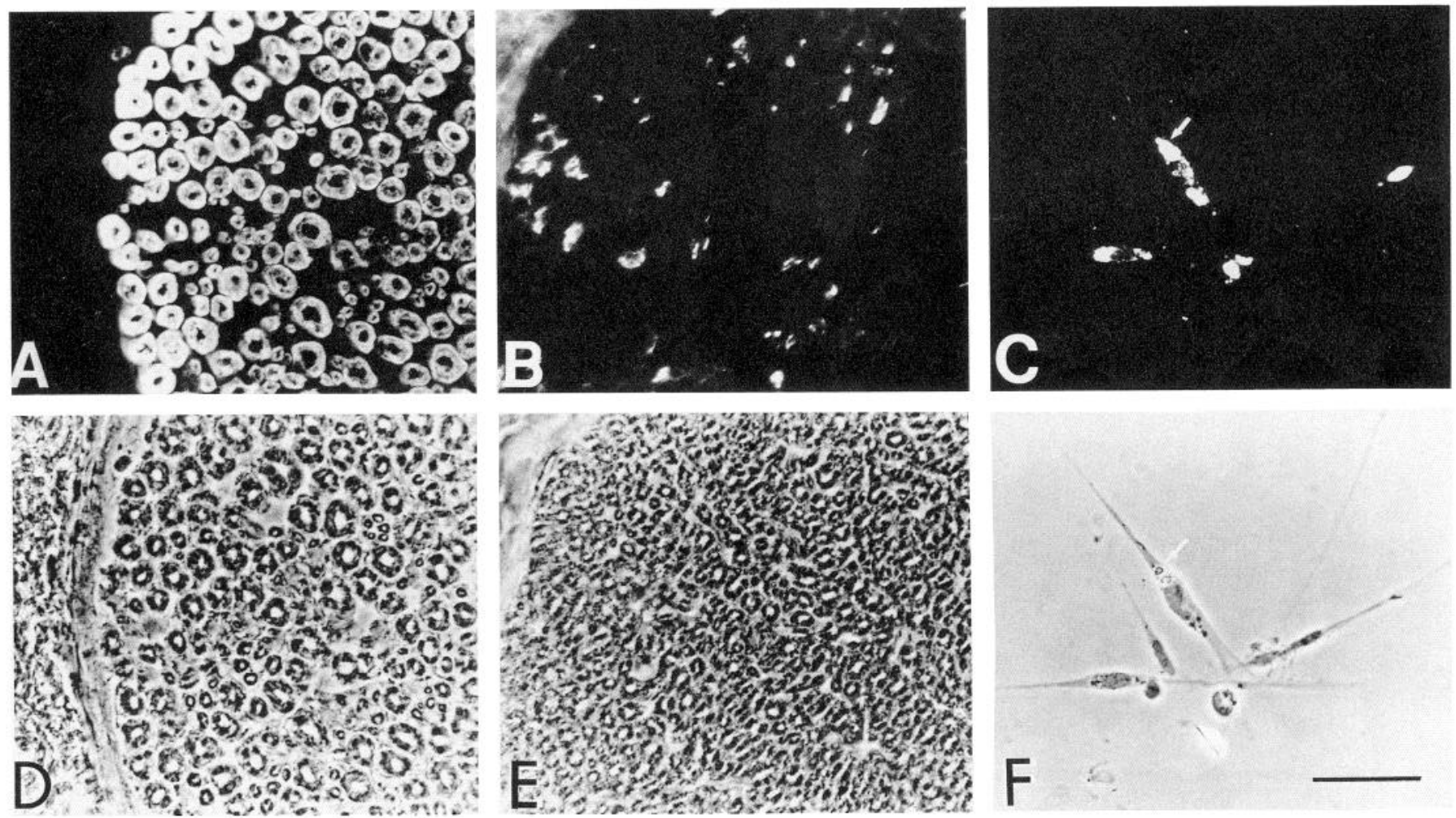

Figure 5. Cross section of normal human peripheral nerve $(A, D)$, normal adult athymic nude rat sciatic nerve $(B, E)$, and purified, dissociated, permeabilized human SCs in culture $(C, F)$ immunostained with the HNK-1 antibody $(A-C)$ and viewed with phase optics $(D-F)$. Human myelin lamellae stain diffusely $(A, D)$ with the HNK-1 antibody whereas rat peripheral nerve $(B, E)$ myelin fails to stain with the HNK-1 antibody. Permeabilized human SCs contain phase refractile intracellular inclusions $(F$, arrow) that stain intensely with the HNK-1 antibody $(C$, arrow). Scale bar, $50 \mu \mathrm{m}$.

dissociated explants of the regenerative cable were also stained for $217 \mathrm{c}$ and $\mathrm{S} 100$ (data not shown) to confirm the migration of rat SCs to this location. An analysis of the cellular distribution of rat and human SCs in regenerated cables obtained after 4 weeks indicated that approximately half of the SCs in the cable were of human origin (Fig. 4).

An occasional human SC could be identified in the proximal or distal stump of the repaired nude rat sciatic nerve, but there was essentially no migration of the human SCs from the implant to these adjacent areas (Fig. 4).

\section{$H N K-1$ staining of adult human and rat peripheral nerves, dissociated human SCs, and the regenerated cable}

Immunostaining of cross sections of adult human peripheral nerve with the HNK-1 antibody results in diffuse staining of the myelin lamellae (Fig. $5 A, D$ ). HNK-1 is a specific marker of human myelin, as this antibody fails to stain rat myelin on similarly prepared cross sections of nude rat sciatic nerve (Fig. $5 B, E)$.

The majority of dissociated human SCs on a collagen-coated surface immunostained in the living state show no HNK-1 surface staining (data not shown). If the cells are first permeabilized and then stained with HNK-1, the intracellular inclusions seen in phase colocalize with intense HNK-1 staining (Fig. $5 C, F$ ). As the HNK-1 antibody diffusely stains human myelin, this suggests that these inclusions represent myelin debris ingested by the human SCs during the period of Wallerian degeneration in vitro. Similarly prepared dissociated rat SCs that have been permeabilized and stained for the HNK-1 antibody do not show any staining of the few intracellular inclusions that they contain.
This further suggests that HNK-1 can be used to label human myelin specifically and is an aid in identifying human SCs containing myelin debris.

Longitudinal sections stained for HNK-1 demonstrate some areas of parallel linear staining, as well as areas of dense focal circular staining (Fig. $6 A, C$ ). In Figure $6 C$, the more intense double linear staining represents a human myelin segment that is indented by the SC nucleus. The contribution of human myelin to the total myelin within the regenerated cable (Fig. 6A) is small, as a consecutive longitudinal section stained with Po (Fig. $6 B$ ) contains numerous myelin segments. Some of the areas of intense focal circular staining (Fig. $6 A, C$ ) seen in longitudinal sections likely represents myelin debris within human SCs that was present within the cells prior to their transplantation into the channel. Channels filled only with $\mathrm{M} / \mathrm{D}$ contained exclusively rat myelin synthesized by rat SCs that had migrated in with regenerating rat axons (Fig. $6 D$ ). These channels were completely $\mathrm{HNK}-1$ negative (Fig. $6 D^{\prime}$ ).

\section{Electron micrographs of the regenerative cable midpoint}

The presence of HNK-1-positive myelin debris within human SCs in culture prior to transplantation and similar-appearing, nonlinear, HNK-1-positive staining in longitudinal and cross sections of the regenerated cable led us to look for SCs containing myelin debris in electron micrographs. Although SCs with myelin debris were not abundant, there were cells with such debris that could be seen either ensheathing or forming myelin segments around regenerating rat axons (Fig. $7 A-C$ ). In electron micrographs of implants that contained the $\mathrm{M} / \mathrm{D}$ matrix alone (in which only rat SCs would be present within the regenerated 

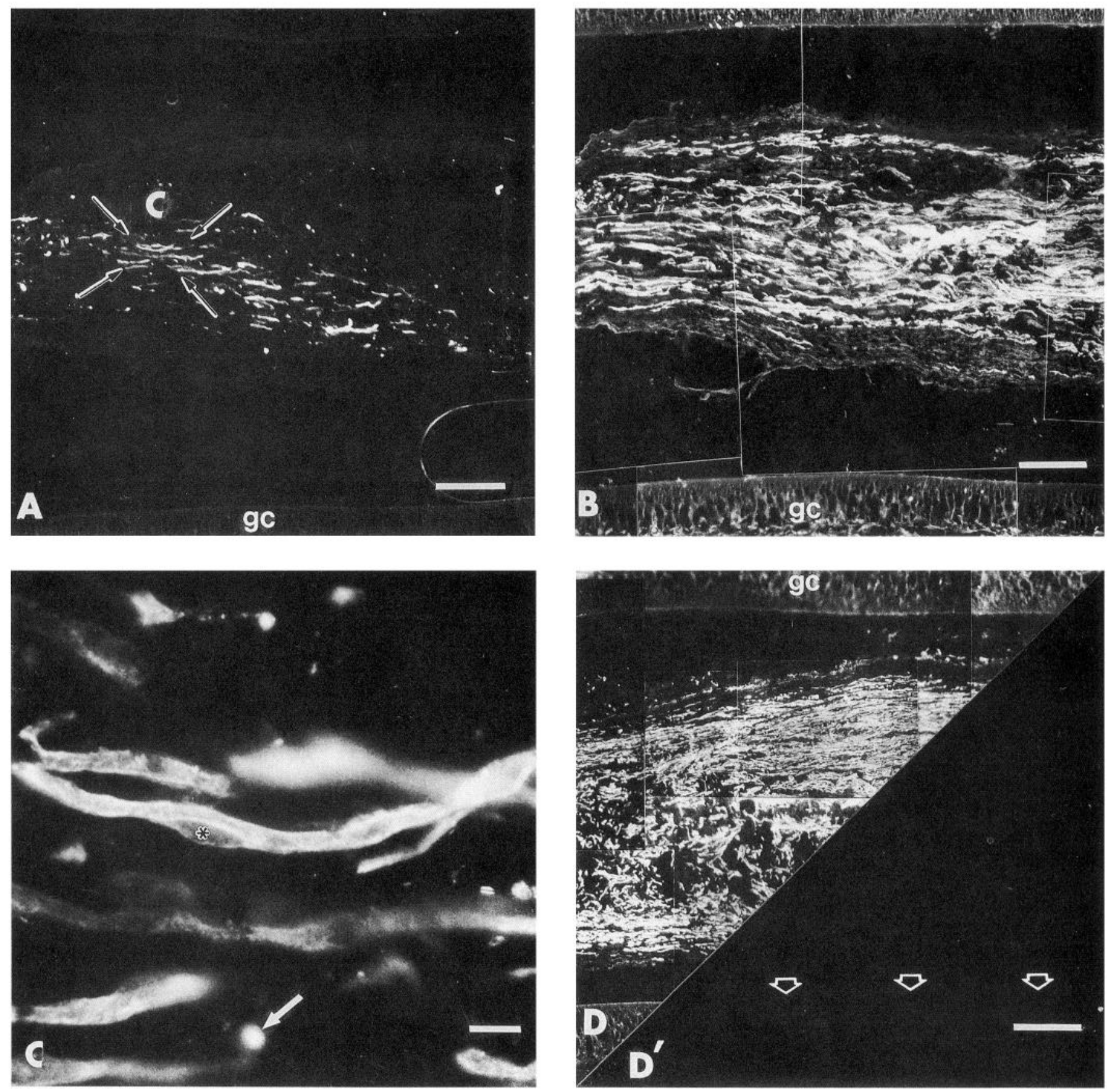

Figure 6. Photomicrographs of longitudinal sections of regenerated cables (2-4 mm from the proximal stump) from guidance channels that contained human SCs (M/D + HSC; $A-C)$ or the M/D matrix alone $\left(D / D^{\prime}\right)$. The cables have been immunostained with either the HNK-1 $(A, C$, $\left.D^{\prime}\right)$ or the Po $(B, D)$ antibody. The regenerated cables occupy the mid-portion of the guidance channel $(g c)$. $A$ and $B$, Human myelin consists of only a fraction of the total myelin present within the regenerated cable. $C$, Higher magnification of the area within arrows in $A$ demonstrates human myelin segments that appear as parallel linear staining. One myelin segment is indented by its SC nucleus $\left({ }^{*}\right)$. Arrow points to intense HNK-1positive myelin debris. $D / D^{\prime}$, Longitudinal section of a regenerated cable that initially contained only M/D. The cable contains Po-positive myelin sheaths $(D)$ but was completely HNK-1 negative $(D)$. The border of the guidance channel is shown by arrows. Scale bars: $A, B$, and $D / D^{\prime}, 100 \mu$ m; $C, 10 \mu \mathrm{m}$.

cable), we failed to identify any SCs with myelin debris. This provides further evidence suggesting that the transplanted human SCs are capable of ensheathing and myelinating rat axons.

Morphometric analysis of regenerated cables in the presence and absence of human SCS

The regenerated cable in both groups consisted of numerous myelinated (Fig. 8A-D) and unmyelinated axons (Table 1) sur- rounded by a distinct epineurium. There was no microfasciculation. In both groups there were areas where the M/D matrix could still be seen. There were significantly more myelinated axons $(p<0.001)$ throughout the entire length of the tube in implants containing human SCs when compared to those implants with the $\mathrm{M} / \mathrm{D}$ matrix alone (Figs. $8 A-D, 9 A$ ). Thus, at the end of 4 weeks the midpoint of cables containing M/D and the human SCs seeded at a density of $80 \times 10^{6}$ cells $/ \mathrm{ml}$ con- 

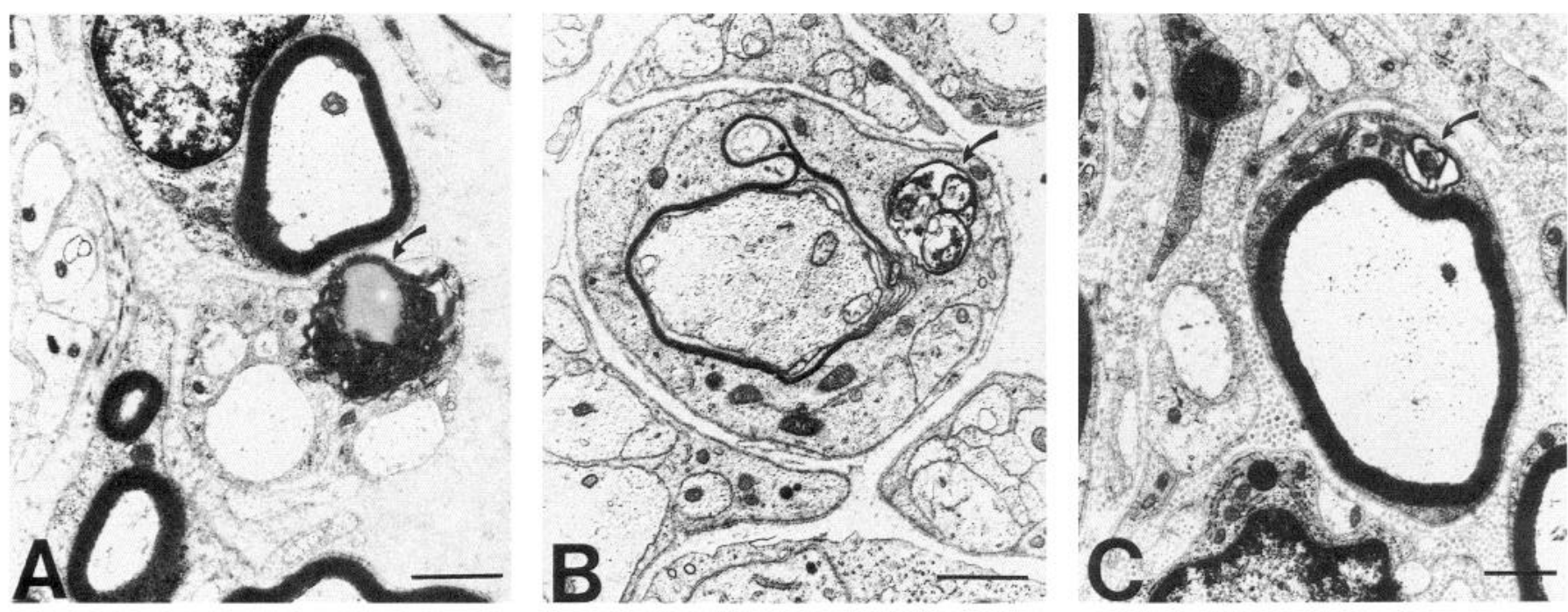

Figure 7. Electron micrographs of SCs presumed to be of human origin containing myelin debris (curved arrow) either ensheathing $(A)$ or myelinating $(B, C)$ regenerating rat axons. Scale bars, $1 \mu \mathrm{m}$.

tained approximately 3000 myelinated axons. This figure compares favorably with the number (2500) of myelinated axons seen in Fisher rats at the midpoint of regenerated cables when $80 \times 10^{6}$ syngeneic SCs had been implanted (Guénard et al., 1992). However, our nude rats contained the implants for a period of 4 weeks rather than the 3 week end-point of the previous study. This number must be also compared to the approximately 8000 myelinated axons in an uninjured rat sciatic nerve (Jenq et al., 1986). An estimate of the number of unmyelinated axons in both groups was made based on the determination of a ratio of the number of unmyelinated to myelinated axons at the cable midpoint. This ratio was similar in both groups (Table 1), and consequently the total number of unmyelinated axons was greater in channels that received the human SCs, as these channels also contained more myelinated axons than the M/D matrix-alone group. There was one implant in the M/D-alone group that contained no cable despite histological confirmation of the presence of both the proximal and distal stumps within the entry and exit of the guidance channel. This implant was not included in the M/D matrix-alone group calculations of the myelinated axon number or cable cross-sectional area.

The cross-sectional area of the cables throughout their entire length was also significantly greater $(p<0.01)$ in channels that received the human SCs (Fig. $8 A, B, 9 B$ ), compared to the M/D matrix-alone channels.

\section{Discussion}

Using an antibody (Ross et al., 1984) to the low-affinity component of the PNGFr, we established that cultured human SCs are capable of surviving when transplanted into the injured peripheral nerve of the immune-deficient rat. The primate NGF receptor has been cloned and its primary amino acid sequence deduced (Johnson et al., 1987). Although the antibody (PNGFr; Ross et al., 1984) will specifically bind to the primate and not the rodent low-affinity NGF receptor, the primate and the rodent NGF receptor have similar molecular weights $(\sim 75 \mathrm{kDa})$ and affinities to ${ }^{125}$ I-NGF (Taniuchi et al., 1986; Johnson et al., 1987). The similar binding properties of both human and rat NGF receptor to ${ }^{125} \mathrm{I}-\mathrm{NGF}$ (isolated from mouse submandibular gland) would support the idea that the ability of the NGFr to bind NGF is conserved between species and that the transplanted human SCs should be capable of presenting neurotrophins within the NGF family to regenerating rat axons (Taniuchi et al., 1986).

In contradistinction to the observations of Aguayo et al. (1976, 1979), who found that there is little migration of host SCs into peripheral nerve grafts, we found a significant migration of the host rat SCs into our implants. This may reflect the differences in the physical properties of the two transplantation paradigms. Peripheral nerve grafts that contain bands of Büngner replete with SCs in basal lamina tubes likely impede further migration of host SCs. On the other hand, our implants that contain SCs organized in a longitudinal array (Guénard et al., 1992) within the $\mathrm{M} / \mathrm{D}$ matrix occupy only a portion of the internal diameter of the tube and could permit rapid migration of host SCs and axons. There was essentially no migration of the transplanted human SCs into the proximal or distal stumps of the host. Labeled rat SCs introduced into a gap within the transected rat sciatic nerve have also been demonstrated not to migrate into the host proximal or distal stumps (Feltri et al., 1992). The

Table 1. Estimation of the number of unmyelinated axons within regenerated cables at their midpoint

\begin{tabular}{|c|c|c|c|c|c|}
\hline \multicolumn{3}{|l|}{$\mathrm{M} / \mathrm{D}$} & \multicolumn{3}{|c|}{$\mathrm{M} / \mathrm{D}+\mathrm{HSC}$} \\
\hline MA & $\begin{array}{l}\text { UMA:MA } \\
\text { ratio }\end{array}$ & EST UMA & MA & $\begin{array}{l}\text { UMA:MA } \\
\text { ratio }\end{array}$ & $\begin{array}{l}\text { EST } \\
\text { UMA }\end{array}$ \\
\hline 1209 & 7.3 & 8826 & 3014 & 3.71 & 11,182 \\
\hline 1629 & 3.28 & 5343 & 3330 & 3.39 & 11,289 \\
\hline \multirow[t]{2}{*}{1732} & 3.15 & 5456 & 2566 & 4.84 & 12,419 \\
\hline & 4.57 & 6542 & & 3.98 & 11,630 \\
\hline
\end{tabular}

Myelinated axon number represents the total number of myelinated axons counted on toluidine blue-stained semithin cross sections at the cable midpoint. The UMA: A ratio was determined by counting numbers of unmyelinated versus myelinated axons by TEM at same level (see Materials and Methods). The estimated number of UMA was calculated by multiplying MA by the UMA:MA ratio. M/D, Matrigel: DMEM in a ratio of 30:70 (v/v); HSC, human Schwann cells; MA, myelinated axons; UMA:MA ratio, unmyelinated to myelinated axon ratio; EST UMA, estimated unmyelinated axon number. 


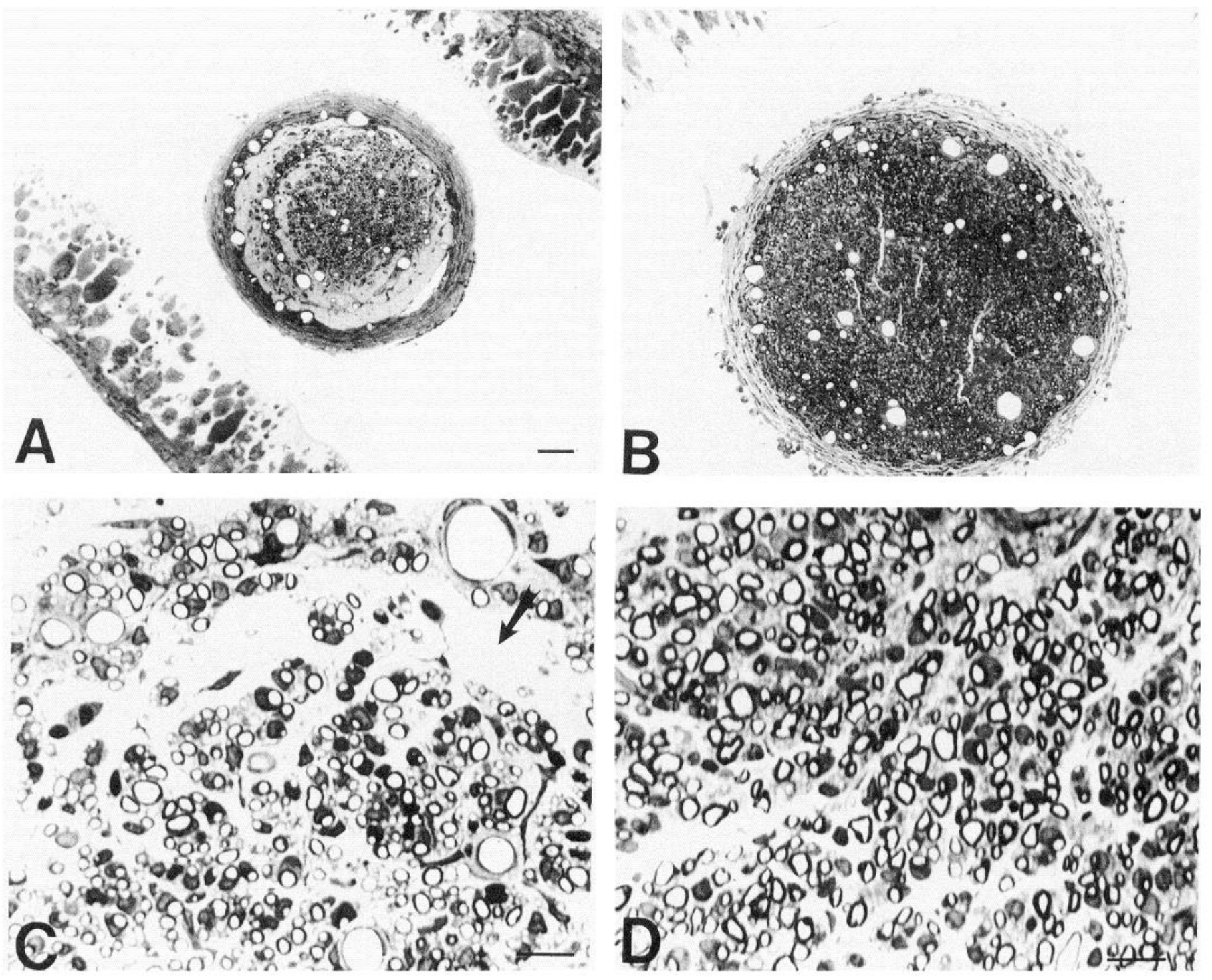

Figure 8. Light micrographs of cross sections of regenerated cables at their midpoint stained with toluidine blue. Guidance channels contained either M/D $(A, C)$ or M/D + HSC $\left(80 \times 10^{6} \mathrm{cells} / \mathrm{ml}\right)(B, D)$ prior to implantation. A distinct epineurial-like structure surrounds the regenerative cables $(A, B)$ in both groups. The cross-sectional cable surface area and the number of myelinated axons are greater in regenerative cables that contained human SCs within the channel prior to transplantation. Arrow in $C$ points to cell-free area representing residual M/D matrix. Scale bars: $A$ and $B, 50 \mu \mathrm{m} ; C$ and $D, 10 \mu \mathrm{m}$.

presence of host SCs within the native matrix of the nerve trunk in these areas could best explain this phenomenon.

The human anti-MAG (myelin-associated glycoprotein) M-protein, an antibody present in some patients with a demyelinating peripheral neuropathy and an IgM monoclonal gammopathy, and the HNK-1 antibody are closely related in their antigen specificity (Latov et al., 1988; Burger et al., 1992). Immune staining of electroblots of homogenates of peripheral nerve with either the M protein or HNK-1 (O'Shannessy et al., 1985; Ilyas et al., 1986) reveals distinct differences between species (human vs rat). HNK-1 binds to a carbohydrate determinant that is shared by a number of glycoproteins and glycolipids that are present in human peripheral nerve myelin. HNK-1 as well as the M-protein will recognize human Po (Bollensen and Schachner, 1987; van den Berg et al., 1990; Field et al., 1992) and human MAG (McGarry, 1983; Nobile-Orazio et al., 1983). It will also recognize two glycosphingolipids containing sulfated glucuronic acid that are present in human mye- lin but are found only at considerably lower concentrations in rat myelin (Ilyas et al., 1986; Kohriyama et al., 1987). HNK-1 immunostaining of human peripheral nerve will stain all myelin sheaths without any reported staining of rat peripheral nerve (Schuller-Petrovic, 1983). Our control sections of human and rat peripheral nerve confirm that the HNK-1 antibody will specifically recognize human but not rat myelin sheaths.

Using the HNK-1 antibody we were able to identify definite human myelin segments within the regenerated cable. There were no human myelin segments within either the proximal or distal stumps of the rat nerve, which is consistent with the lack of PNGFr-positive human SCs in these areas. The number of Po-positive myelin segments greatly outnumbered the HNK-1positive segments on any cross- or longitudinal section (Fig. $6 A, B)$. This indicated that despite an approximately equal number of human and rat SCs in the implant (as determined by the culture techniques described above) at 4 weeks, the rat SCs were far more successful in myelinating the regenerating rat axons. 
In addition HNK-1-positive myelin segments were never detected in the distal quarter of the regenerated cable despite the presence of myelin throughout the cable. Since axons are only arriving at the distal stump between the second to third week (Williams et al., 1983), this suggests that a longer period of axonal contact may be necessary to induce the human SCs to myelinate when compared to the host rat SCs. This is also consistent with the findings of Aguayo et al. (1979), who found that a mature myelin structure took much longer to develop in human xenografts compared to mouse allografts. As suggested by the above authors, this may be due to true species differences in the speed of myelination, or the "peculiar axon-SC interactions in the xenografted nerves."

A conspicuous feature of dissociated human SCs obtained from adult peripheral nerve is the presence of large amounts of intracellular debris in some cells. The phase refractile qualities of this debris and the fact that the explants undergo "Wallerian degeneration" while in culture lead us to believe that they represent ingested myclin. As similarly prepared rat SCs contain much less debris, we have speculated that while in culture the human SCs do not contain sufficient quantities of the necessary enzymatic machinery to process the ingested myelin rapidly. When human SCs are permeabilized, the myelin debris within them stains intensely with the HNK-1 antibody. Similarly prepared rat SCs do not stain, further supporting the view that the HNK-1 antibody specifically recognizes human myelin. When channels containing only $\mathrm{M} / \mathrm{D}$ were transplanted, the regenerated cables were completely HNK-1 negative despite the presence of rat myelin as demonstrated by the presence of Po staining. This further supports the view that the HNK-1 antibody specifically recognizes human myelin within the regenerated cables containing the human SCs.

It has long been recognized (Reich, 1903) that with advancing age, SCs within human peripheral nerves accumulate metachromatic granules ( $\pi$ granules). These granules are located in the cytoplasm of SCs in a perinuclear location and tend to occur within in the large myelinated fibers. These granules are also found in the peripheral nerves of dogs and goats, but are absent in the rat, rabbit, guinea pig, and fish (Noback, 1953; Leibowitz et al., 1983). They are felt to be secondary lysosomes (Weller and Herzog, 1970), which contain undigested myelin (Noback, 1953). Leibowitz et al. (1983) have shown that the human antiMAG M-protein has a higher affinity to these partially processed myelin fragments than to the native myelin itself. Since HNK1-positive intracellular inclusions are present in our cultured human SCs, we believe that the $\pi$ granules within the native aging human nerve represent the same histological and immunological end-points of "dysfunctional" myelin degradation, which appear to be to some extent species specific.

As myelin debris is present within the human SCs prior to their transplantation into the semipermeable guidance channels, and this myelin stains with the HNK-1 antibody, it is critical for us to distinguish between this "old" partially processed myelin and any "new" human myelin that has formed around regenerating rat axons. Longitudinal sections of the regenerated cable provide the best opportunity to distinguish between these two possibilities. In these sections we see two types of HNK-1 staining: one type is relatively small, focal staining that we bclieve represents myelin debris within human SCs, and the other is parallel linear stripes, which represents newly synthesized human myelin encircling rat axons.

It is unusual for rodent SCs to contain myelin debris 4 weeks
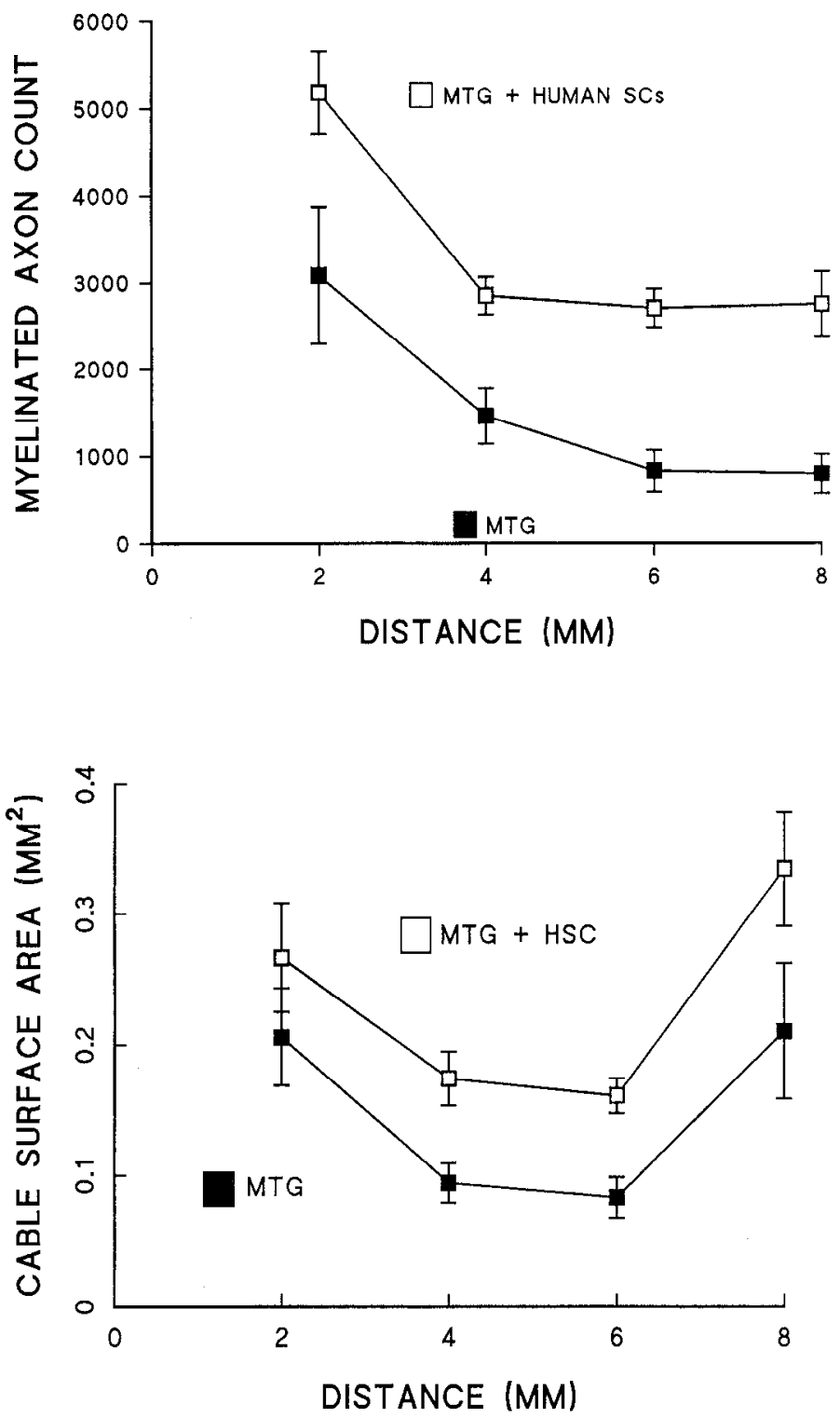

Figure 9. The number of myelinated axons $(p<0.001)(A)$ and crosssectional area $(p<0.01)(B)$ of regenerated cables $2,4,6$, and $8 \mathrm{~mm}$ from proximal stumps was significantly greater in channels containing human SCs $(n=6)$ when compared to channels containing the M/D matrix alone $(n-7)$. Data represent the means \pm SEM. $M T G$, Matrigel.

after injury. In mice that received sciatic nerve autografts (Hall, 1986a), myelin debris is seen only in the occasional macrophage within the autograft 1 month after repair. Similarly, TEMs of regenerated cables of transplanted rat SCs (Guénard et al., 1992) or the controls in our study containing M/D alone (and hence only rat SCs), we never found large fragments of myelin debris. Therefore, one can suspect that fragments of human myelin debris, which in our longitudinal sections are seen as focal HNK-1 staining, will be seen within SCs present in our regenerative cables when examined at the electron microscopic level. Myelin debris, although not frequent, can be seen in SCs that are associating with or myelinating rat axons. We feel that this is an indirect way of identifying human SCs and provides further supportive evidence for the functional capabilities of human SCs in this experimental paradigm.

In both the M/D and the M/D + HSC groups there were 
more axons in the proximal portions of the regenerative cable than at the distal end. The presence of significantly more myelinated axons throughout the entire length of the cable in the presence of the added human SCs indicates that they strongly promote axonal regeneration. The addition of constituents of the PNS within tubes to enhance regeneration has been a goal in devising alternative methods for the repair of damaged peripheral nerves pursued by several groups. Previous reports have demonstrated that insertion of isolated segments of peripheral nerve within or at the end (Jenq and Coggeshall, 1986a,b) of silicone chambers can enhance axonal regeneration. Initial attempts to introduce populations of cells cultured from the PNS into tubes (Shine et al., 1985) have also been successful in promoting regeneration even in the absence of a distal stump. However, these cultures consisted of a mixed population of cells (neurons, SCs, and fibroblasts) and therefore the exact role of each cell type's contribution to the regencrative process could not be evaluated. The recent ability to obtain large populations of purified SCs from adult peripheral nerve (Morrissey et al., 1991a) has been followed by the demonstration that SCs isolated from their native matrix can enhance axonal regeneration when presented within a matrix to the regenerating PNS (Guénard et al., 1992). The addition of humoral factors such as NGF (Rich et al., 1989), acidic fibroblast growth factor (Cordeiro et al., 1989), or basic fibroblast growth factor (Danielsen et al., 1988) within the lumen of impermeable channels has also been shown to enhance early regenerative events. They may act directly on neurons or indirectly through non-neuronal cells. The addition of factors that enhance axonal regeneration may be a useful adjunct to increase regeneration further through $\mathrm{SC}$-seeded guidance channels.

This study has established that human SCs isolated from peripheral nerve are capable of myelination. This finding together with the recent ability to produce a mitotically active population of human SCs in culture clearly opens the possibility of using an autotransplantation paradigm for the repair of human central and peripheral nerve injuries. We are pursuing a number of issues that still need to be addressed before such an autotransplantation paradigm could be used clinically. These include the following questions. Why do human SCs perform relatively poorly compared to the rat SCs in myelinating regenerating rat axons? Can the purity of populations of human SCs be maintained during mitogenic expansion by modifying existing techniques? Will human SCs expanded in culture retain their ability to promote regeneration and myelinate regenerating rat axons? Finally, will these human SCs retain normal growth characleristics (and not form tumors when transplanted) after expansion on mitogens?

\section{References}

Acheson A, Barker PA, Alderson RF, Miller FD, Murphy RA (1991) Detection of brain-derived neurotrophic factor-like activity in fibroblasts and Schwann cells: inhibition by antibodies to NGF. Neuron 7:265-275.

Aebischer P, Guénard V, Winn SR, Valentini RF, Galletti PM (1988) Blind ended semi-permeable guidance channels support peripheral nerve regeneration in the absence of a distal nerve stump. Brain Res 454:179-187.

Aebischer P, Wahlberg L, Tresco PA, Winn SR (1991) Macroencapsulation of dopamine-secreting cells by coextrusion with an organic solution. Biomaterials 12:50-56.

Aguayo AJ, Epps J, Charron L, Bray GM (1976) Multipotentiality of Schwann cells in cross-anastomosed and grafted myelinated and un- myelinated nerves: quantitative microscopy and radioautography. Brain Res 104:1-20.

Aguayo AJ, Kassarhan J, Skamene E, Kongshavn P, Bray GM (1977) Myelination of mouse axons by Schwann cells transplanted from normal and abnormal human nerve. Nature 268:753-755.

Aguayo AJ, Perkins S, Duncan I, Bray G (1978) Human and animal neuropathies studied in experimental nerve transplants. In: Peripheral neuropathies (Canal N, Pozza G, eds), pp 37-48. New York: Elsevier/ North Holland.

Aguayo AJ, Bray GM, Perkins CS, Duncan ID (1979) Axon-sheath cell interactions in peripheral and central nervous system transplants. Soc Neurosci Symp 4:361-383.

Berry M, Hall S, Follows R, Rees L, Gregson N, Sievers J (1988) Response of axons and glia at the site of anastomosis between the optic nerve and cellular or acellular sciatic nerve grafts. J Neurocytol 17:727-744.

Bollensen E, Schachner M (1987) The peripheral myelin glycoprotein Po expresses the L2/HNK-1 and L3 carbohydrate structures shared by neural adhesion molecules. Neurosci Lett 82:77-82.

Bunge RP, Bunge MB (1983) Interrelationship between Schwann cell function and extracellular matrix production. Trends Neurosci 6:499505 .

Burger D, Perruisseau G, Simon M, Steck AJ (1992) Comparison of the N-linked oligosaccharide structures of the two major human myelin glycoproteins MAG and Po: assessment of the structures bearing the epitope for HNK-1 and human monoclonal immunoglobulin M found in demyelinating neuropathy. J Neurochem 58:854-861.

Cabasso F (1980) Hollow fiber membranes, In: Encyclopedia of chemical tcchnology, Vol 12 (Kirk-Othner, ed), pp 492-517. New York: Wiley.

Cordeiro PG, Seckel BR, Lipton SA, D'Amore PA, Wagner J, Madison $R$ (1989) Acidic fibroblast growth factor enhances peripheral nerve regeneration in vivo. Plast Reconstr Surg 83:1013-1019.

Danielsen N, Pettmann B, Vahlsing HL, Manthorpe M, Varon S (1988) Fibroblast growth factor effects on peripheral nerve regeneration in a silicone chamber model. J Neurosci Res 20:320-330.

Daniloff JK, Levi G, Grumet M, Rieger F, Edelman GM (1986) Altered expression of neuronal cell adhesion molecules induced by nerve injury and repair. J Cell Biol 103:929-945.

David S, Aguayo AJ (1981) Axonal elongation in peripheral nervous system "bridges" after central nervous system injury in adult rat. Science 214:391-393.

Feltri LM, Scherer SS, Wrabetz L, Kamholz J, Shy ME (1992) Mitogen-expanded Schwann cells retain the capacity to myelinate regenerating axons after transplantation into rat sciatic nerve. Proc Natl Acad Sci USA 89:8827-8831.

Field MC, Wing DR, Dwek RA, Rademacher TW, Schmitz B, Bollensen E, Schachner M (1992) Detection of multisulphated N-linked glycans in the L2/HNK-1 carbohydrate epitope expressing neural adhesion molecule Po. J Neurochem 58:993-1000.

Friedman B, Scherer SS, Rudge JS, Helgren M, Morrisey D, McClain J, Wang D-Y, Wiegrand SJ, Furth ME, Lindsay RM, Ip NY (1992) Regulation of ciliary neurotrophic expression in myelin related Schwann cells in vivo. Neuron 9:295-305.

Guénard V, Kleitman N, Morrissey TK, Bunge RP, Aebischer P (1992) Syngeneic Schwann cells derived from adult nerves seeded in semipcrmcablc guidance channels enhance peripheral nerve regeneration. J Neurosci 12:3310-3320.

Hall SM (1986a) Regeneration in cellular and acellular autografts in the peripheral nervous system. Neuropathol Appl Neurobiol 12:2746.

Hall SM (1986b) The effect of inhibiting Schwann cell mitosis on the reinnervation of acellular autografts in the peripheral nervous system. Neuropathol Appl Neurobiol 12:401-414.

Heumann R, Korsching S, Bandtlow C, Thoenen H (1987) Changes of NGF synthesis in non-neuronal cells in response to sciatic nerve transection. J Cell Biol 104:1623-1631.

Ilyas AA, Dalakas MC, Brady RO, Quarles RH (1986) Sulfated glucuronyl glycolipids reacting with anti-myelin associated glycoprotein monoclonal antibodies including IgM paraproteins in neuropathy: species distribution and partial charactcrization of the epitope. Brain Res 385:1-9.

Jenq C-B, Coggeshall RE (1986a) The effects of an autologous transplant on patterns of regeneration in rat sciatic nerve. Brain Res 364: 45-56. 
Jenq C-B, Coggeshall RE (1986b) Regeneration of transected rat sciatic nerves after using isolated nerve fragments as distal inserts in silicone tubes. Exp Neurol 91:154-162.

Jenq C-B, Kyungsoon C, Coggeshal RE (1986) Postnatal loss of axons in normal rat sciatic nerve. J Comp Neurol 244:445-450.

Johnson D, I anahan A, Buck R, Sehgal A, Morgan C, Mercer E, Bothwell M, Chao M (1986) Expression and structure of the human NGF receptor. Cell 47:545-554.

Kleitman N, Wood PM, Bunge RP (1991) Tissue culture methods for studying myelination. In: Culturing nerve cells (Banker $\mathrm{G}$, Goslin $\mathrm{K}$, eds), pp 337-377. Cambridge, MA: MIT Press.

Kohriyama T, Kusunoki S, Ariga T, Yoshino JE, DeVries GH, Latov $\mathrm{N}, \mathrm{Yu}$ RK (1987) Subcellular localization of sulfated glucuronic acid-containing glycolipids reacting with anti-myelin-associated glycoprotein antibody. J Neurochem 48:1516-1522.

Kromer LF, Cornbrooks CJ (1987) Identification of trophic factors and transplanted cellular environments that promote CNS axonal regeneration. Ann NY Acad Sci 495:207-224.

Latov N, Hays AP, Sherman WH (1988) Peripheral neuropathy and anti-MAG antibodies. CRC Crit Rev Neurobiol 3:301-332

Leibowitz S, Gregson NA, Kennedy M, Kahn SN (1983) IgM paraproteins with immunological specificity for a Schwann cell component and peripheral nerve myelin in patients with polyneuropathy. $J$ Neurol Sci 59:153-165.

Levi ADO, Guénard V, Aebischer P, Bunge RP (1992) The functional properties of purified populations of cultured human Schwann cells studied in vivo. Soc Neurosci Abstr 18:964.

Martini R, Schachner M (1986) Immunoelectron microscopic localization of neural cell adhesion molecules (L1, N-CAM, and MAG) and their shared carbohydrate epitope and myelin basic protein in developing sciatic nerve. J Cell Biol 103:2439-2448.

McGarry RC, Helfand SL, Quarles RH, Roder JC (1983) Recognition of myelin-associated glycoprotein by the monoclonal antibody HNK1. Nature 306:376-378.

Millesi H (1990) Peripheral nerve surgery today: turning point or continuous development? J Hand Surg 15:281-287.

Morrissey TK, Kleitman N, Bunge RP (1991a) Isolation and functional characterization of Schwann cells derived from adult peripheral nerve. J Neurosci 11:2433-2442.

Morrissey TK, Kleitman N, Bunge RP (1991b) Functional characteristics of adult derived rat, monkey, and human SCs studied in vitro. Soc Neurosci Abstr 17:376.

Noback CR (1953) The protagon ( $\pi$ ) granules of Reich. J Comp Neurol 99:91-101.

Nobile-Orazio E, Hays AP, Latov N, Perman G, Golier J, Shy ME, Freddo L (1984) Specificity of mouse and human monoclonal antibodies to myelin-associated glycoprotein. Neurology 34:1336-1342.

O'Shannessy DJ, Willison HJ, Inuzuka T, Doberson MJ, Quarles RH
(1985) The species distribution of nervous system antigens that react with anti-myelin-associated glycoprotein antibodies. J Neuroimmunol 9:255-268.

Paino CL, Bunge M (1991) Induction of axonal growth into Schwann cell implants into lesioned adult rat spinal cord. Exp Neurol 114:254257

Pleasure D, Kreider B, Sobue G, Ross AH, Koprowski H, Sonnenfeld $\mathrm{KH}$, Rubenstein AE (1986) Schwann-like cells cultured from human dermal neurofibromas. Ann NY Acad Sci 486:227-240.

Ramon y Cajal S (1928) Degeneration and regeneration of the nervous system. New York: Hafner.

Reich F (1903) Ueber eine neue Granulation in der Nervenzellen. Arch Anat Physiol 208-214.

Rich KM, Alexander TD, Pryor JC, Hollowell JP (1989) Nerve growth factor enhances regeneration through silicone tubes. Exp Neurol 105: $162-170$

Ross AH, Grob P, Bothwell M, Elder DE, Ernst CS, Marano N, Ghrist BFD, Slemp CC, Herlyn M, Atkinson B, Koprowski H (1984) Characterization of nerve growth factor receptor in neural crest tumors using monoclonal antibodies. Proc Natl Acad Sci USA 81:6681-6685.

Rutkowski JL, Tennekoon GI, McGillicuddy JE (1992) Selective culture of mitotically active human Schwann cells from adult sural nerves. Ann Neurol 31:580-586.

Schuller-Petrovic S, Gebhart W, Lassmann H, Rumpold H, Kraft D (1983) A shared antigenic determinant between natural killer cells and nervous tissue. Nalure 306:179-181.

Shine HD, Harcourt PG, Sidman RL (1985) Cultured peripheral nervous system cells support peripheral nerve regeneration through tubes in the absence of distal nerve stump. J Neurosci Res 14:393-401.

Smith GV, Stevenson JA (1986) Peripheral nerve grafts lacking viable Schwann cells fail to support central nervous system axonal regeneration. Exp Brain Res 69:299-306.

Taniuchi M, Brent Clark H, Schweitzer JB, Johnson EM (1988) Expression of nerve growth factor receptor by Schwann cells of axotomized peripheral nerves: ultrastructural location, suppression by axonal contact, and binding properties. J Neurosci 8:664-681.

van den Berg LH, Sadiq SA, Thomas FP, Latov N (1990) Characterization of HNK-1 bearing glycoproteins in human peripheral nerve myelin. J Neurosci Res 25:295-299.

Weller RO, Herzog I (1970) Schwann cell lysosomes in hypertrophic neuropathy and in normal human nerves. Brain 93:347-356.

Williams LR, Longo FM, Powell HC, Lundborg G, Varon S (1983) Spatial-temporal progress of peripheral nerve regeneration within a silicone chamber: parameters for a bioassay. J Comp Neurol 218: $460-470$.

Xu XM, Guénard V, Kleitman N, Bunge MB (1992) Axonal growth into Schwann cell-seeded channels grafted into transected adult rat spinal cord. Soc Neurosci Abstr 18:1479. 